Araştırma Makalesi / Research Paper

\title{
Beyşehir Gölü Havzasının Yeraltısuyu Akım Modellemesi Esaslı Hidrojeolojik Özelliklerinin Değerlendirilmesi
}

\author{
İskender SOYASLAN ${ }^{*}$, Kerem HEPDENIZ² \\ ${ }^{1}$ Mehmet Akif Ersoy Üniversitesi, Mühendislik-Mimarlık Fakültesi, Burdur \\ ${ }^{2}$ Mehmet Akif Ersoy Üniversitesi, Bucak Emin Gülmez Teknik Bilimler Meslek Yüksekokulu, Burdur \\ Geliş Tarihi (Received): 27.11.2017, Kabul Tarihi (Accepted): 12.02.2018 \\ $\square$ Sorumlu Yazar (Corresponding author*): isoyaslan@mehmetakif.edu.tr \\ (C) +902482132717 皿 +902482132704
}

$\overline{\text { ÖZ }}$

Bu çalışmada, Isparta ve Konya il sınırları içerisinde yer alan Beyşehir Gölü Havzasının hidrolojik ve hidrojeolojik açıdan genel bir değerlendirilmesi yapılmıştır. Yeraltısuyu havzalarında yapılacak yeraltısuyu akım modellemelerinde, birimlerin hidrojeolojik özelliklerinin ve yeraltı jeolojisinin belirlenmesi büyük önem taşımaktadır. Bu çalışmanın temel amacı, Beyşehir Gölü havzası için yapılacak yeraltısuyu akım modellemesinde kullanılacak hidrojeolojik özelliklerin belirlenmesidir. Beyşehir Gölü havzası; Şarkikaraağaç, Kıreli, Sarısu, Karadiken, Üstünler, Yeşildağ, Yenişarbademli ve Gedikli olmak üzere sekiz alt havzaya ayrılmıştı. Beyşehir Gölü havzası $4121 \mathrm{~km}^{2}$ 'lik bir alana sahip olup, alt havzalardan en büyüğü $1134 \mathrm{~km}^{2}$ lik alanı ile Sarısu havzası, en küçüğü ise 58 km²'lik alanı ile Karadiken havzasıdır. Çalışma alanında bulunan jeolojik birimler hidrojeolojik özelliklerine göre ayrıntılı olarak değerlendirilmiştir. Litolojik birimler hidrojeolojik özelliklerine göre; Taneli Gözenekli Akifer Ortam (Akf1), Erime Çatlaklı Kaya Akifer Ortam (Akf2), Akitard Ortam (Akt), Akiklüd Ortam (Akl), Akifüj Ortam 1 (Akj1) ve Akifüj Ortam 2 (Akj2) olmak üzere altı alt sınıf ayırt edilmiştir. Çalışma alanı için yapılacak yeraltısuyu akım modellemesinde kullanılacak model grid ağları ve modelleme önerileri verilmiştir.

Anahtar Kelimeler: Beyşehir Gölü, Havza, Yeraltısuyu, Hidrojeoloji, Modelleme

\section{Evaluation of Hydrogeological Features Based on Groundwater Flow Mode- ling in the Beyşehir Lake Basin}

\begin{abstract}
In this study, a general evaluation of hydrological and hydrogeological aspects of the Beysehir Lake Basin located within the provinces of Isparta and Konya was made. In groundwater flow models to be made in groundwater basins, the hydrogeological properties of the units and the determination of the underground geology are of great importance. The main purpose of this study is to determine the hydrogeological properties to be used in groundwater flow model for the basin of Lake Beyşehir. Beyşehir Lake basin; There were eight sub-basins, namely Şarkikaraağaç, Kıreli, Sarısu, Karadiken, Üstünler, Yeşildağ, Yenişarbademli and Gedikli. The Beyşehir Lake basin has an area of 4121 $\mathrm{km}^{2}$, the largest of which is the $1134 \mathrm{~km}^{2}$ area and the Sarısu basin, and the smallest is the Karadiken basin with 58 $\mathrm{km}^{2}$. The geological units in the study area have been evaluated in detail according to their hydrogeological properties. According to hydrogeological features of lithological units; There are six subclasses classified as Granular Porous Aquifer (Akf1), Cratered Rock Aquifer Medium (Akf2), Aquitard Medium (Akt), Aquiclude Medium (Akl), Aquifuge Medium 1 (Akj1) and Aquifuge Medium 2 (Akj2). Model grid networks to be used in groundwater flow model for the study area and modeling proposal are given.
\end{abstract}

Keywords: Beysehir Lake, Basin, Groundwater, Hydrogeology, Modelling 


\section{Giriş}

Beyşehir Gölü, Türkiye'nin güney batısında yer alan ve Göller Bölgesi olarak isimlendirilen, içerisinde çok sayıda göl ve baraj gölünü barındıran bir bölge içerisinde yer almaktadır. Göller Bölgesinin doğusunda yer alan Beyşehir Gölü ise Van ve Tuz gölünden sonra Türkiye'nin 3. büyük gölü ve daha da önemlisi en büyük tatlı su gölüdür. Beyşehir Gölü Havzası, İç Anadolu Bölgesi'nin en büyük kapalı havzası olan Konya Kapalı Havzası'nın en önemli tatlı su kaynağıdır. Gölden halen içme suyu temini (Beyşehir İlçesi ve 7 kasaba), tarımsal sulama (Konya Ovası, Şarkikaraağaç ve Kıreli pompaj sulaması), balıkçılık ve turizm başta olmak üzere çok amaçlı olarak faydalanılmaktadır. Beyşehir Gölü sahip olduğu doğal güzellikleri, ev sahipliği yaptığı biyolojik çeşitlilik ve Türkiye'nin en büyük tatlı su kaynağı olması nedeniyle büyük bir öneme sahiptir.

Türkiye'de 14 Ramsar Alanı, 45 Ulusal Öneme Haiz Sulak Alan, 8 Mahalli Öneme Haiz Sulak Alan bulunmasına rağmen, Beyşehir Gölü bu alanlara dahil edilmemiştir. Ancak Beyşehir gölü ve çevresi; Milli Park Koruma Alanı (Beyşehir Gölü ve Kızıldağ Milli Parkı), İçme ve Sulama Suyu Rezervi Koruma Alanı, uluslararası önemi olan A grubu sulak alan, tarihi ve kültürel zenginliği bakımından siT Alanı olarak belirlenmiştir.

Çevre kirliliği ve küresel ısınmanın etkilerinin çok daha iyi görüldüğü günümüzde, kullanılabilir su kaynaklarının önemi giderek artmıştır. Bu artışa paralel olarak, Beyşehir Gölü sorunlarının belirlenmesine yönelik çalışmalarda artmaktadır. Gölün temel olarak özellikle göl su kalitesi ve miktarı ile de ilgili olmak üzere; yağışların yetersizliği ve gölden fazla su çekimi, gölün kirlenmesi, biyolojik çeşitliliğin tehdit altında olması ve idari yönden çok başlılık temel sorunlar olarak görünmektedir (Doğan ve ark., 2013).

Beyşehir Gölü Havzasında daha önceki çalışmalarda, Beyşehir Gölü su seviye ölçümlerine ilave olarak Manavgat Çayı, Köprü Çay akımları ile Beyşehir ve Manavgat Devlet Meteoroloji İstasyonlarındaki (DMi) yağış verilerinin 2008 öncesi ve sonrasına ait çoklu korelasyon ilişkileri incelenmiştir. Sonuçta olası iklim verisiyle gölden sulama için ne kadar çekim yapılması gerektiği ve gölün işletme kotunun ne olması gerektiği konusunda optimizasyon modeli oluşturulmuştur (Doğan ve ark., 2013).

Beyşehir Gölü Havzası'nda Beyşehir, Derbent, Hüyük, Şarkikaraağaç ve Yenişarbademli olmak üzere 5 ilçe merkezi bulunmaktadır. Bu ilçelerden sadece Beyşehir Belediyesi'nin atıksu artıma tesisi vardır. Havzadaki kirlilik kaynakları, evsel ve endüstriyel atıksular, tarımsal arazilerde kullanılan gübre ve tarımsal ilaçlardır. Yerleşim alanlarının atıksuları genel olarak herhangi bir arıtma işlemine tabi tutulmaksızın derelere veya boş araziye verilmektedir (Hoşafçıoğlu, 2007).

Genel olarak Beyşehir Gölü'nde; Kasım ayından Nisan ayına kadar gölden su kaçağı ve Mayıs ayından Ekim ayına kadar da gölde beslenme meydana gelmektedir. Yani su çekildiğinde gölde beslenme, göle suların ulaştığı zaman ise gölde kaçak meydana gelmektedir (Mercan, 2006). Beyşehir Gölü, Suğla Gölü, Apa Barajı kanallarla birbirine bağlanarak suyun fazla olduğu bölgeden az olan bölgeye aktarımı söz konusudur. Göl seviyesi ve gölden çekilen su miktarı birbiri ile direkt ilişkili olarak yıldan yıla değişim göstermektedir (Yarar, 2004).

Gölün maksimum işletme kotu olan 1125 m'deki hacmi ise $5234,5 \mathrm{hm}^{3}$ olarak hesaplanmaktadır. Beyşehir Gölü Regülatörün işletme açılmasından itibaren seviye gözlemlerine göre göl su seviyesi 1120,85 m ile 1125,50 m arasında değişmiştir (DSI, 1996). En düşük su seviyesi olan 1120,85 m ile 1934 yılı sonunda, en yüksek su seviyesi olan 1125,50 m'de 1981 yılında ölçülmüştür. En yüksek göl su seviyesi kotunda göl yüzeyi 745 km²'ye ulaşmıştır (Ayhan ve ark., 1996).

Gölün beslenmesi yağıştan, yüzeysel akıştan, yeraltısuyu akışı ile boşalımı ise buharlaşma, yeraltı akışı yani sızma ile sulama suyu ve kullanma suyu alınması ile gerçekleşmektedir. Göl alanının geniş olması sebebiyle göl alanından buharlaşan su miktarı kaybı önemlidir. Gölden kaçaklarla su kaybı, Aralık ayı başı ile Mayıs sonu Haziran başında olmaktadır. Bu kaçaklar, göl kotu 1123 m seviyesine ulaştığında başlamaktadır (Ekmekçi, 1987). Gölden, Manavgat Çayı'nı besleyen kaynaklara düdenlerle su boşalımı olduğu bilinmektedir (Kazancı ve ark., 2003).

\section{MATERYAL VE YÖNTEM}

\section{Çalışma alanı}

Çalışma alanı Türkiye'nin önemli karst bölgelerinden biri olan Toros Karst Kuşağının Batı Toroslar kesiminde Isparta Büklümü içerisinde yer almaktadır. Devlet Su İşleri (DSi) tarafından hazırlanmış olan "Türkiye Akarsu Havzaları Haritası" 'nda ülkemiz 25 akarsu havzasına ayrılmıştır. Türkiye akarsu havzaları haritasına göre Beyşehir Gölü Havzası, Konya Kapalı Havzası içerisinde yer almaktadır (DSi, 2017). Beyşehir Gölü havzasının kuzeyinde Akarçay havzaları, kuzey doğusunda Sakarya Havzası, doğusunda Konya Kapalı Havzasına içerisinde yer alan Çumra havzası, güney ve batısında ise Antalya Havzası bulunmaktadır (Şekil 1). 


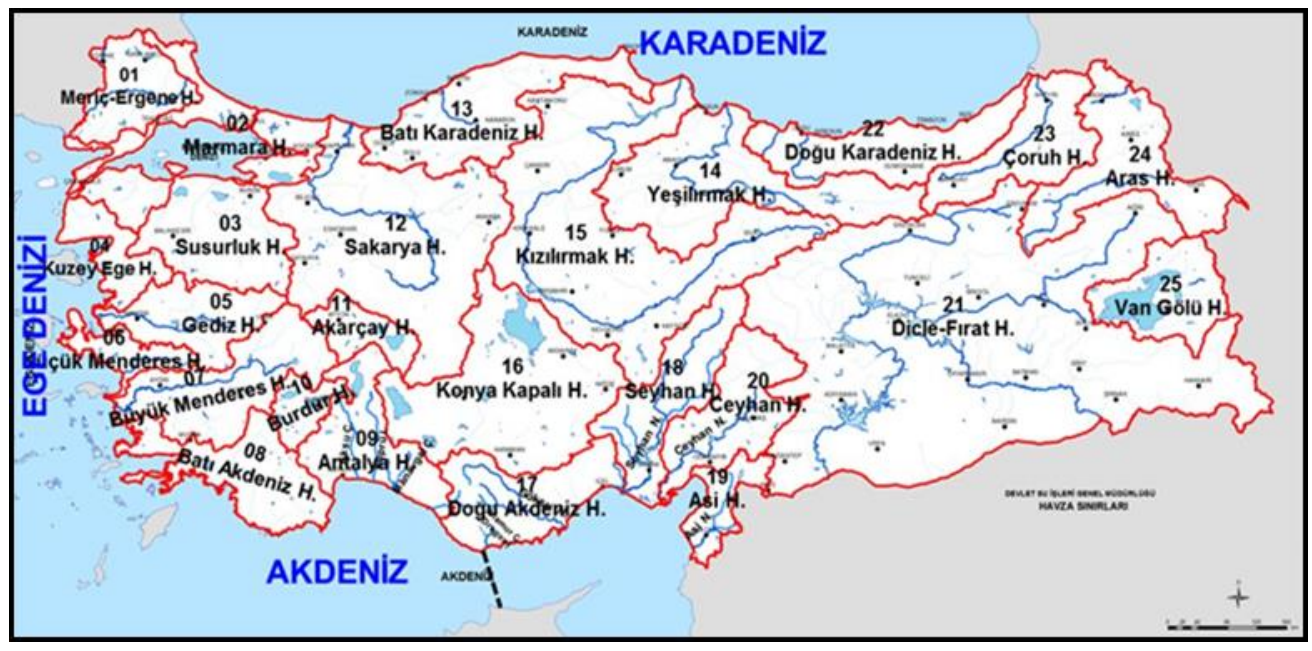

Şekil 1. Türkiye akarsu havzaları haritası (DSi, 2017)

Konya ve Isparta il sınırı içerisinde yer alan Beyşehir Gölü Su Toplama Havzası, yaklaşık $4121 \mathrm{~km}^{2}$ büyüklüğü ile Türkiye'nin en büyük tatlı su gölüdür. Göl alanının yaklaşık olarak \%80'i Konya il sınırlarında ve geriye kalan \%20'si ise Isparta il sınırları içinde yer almakta olup, Beyşehir Gölü çevresindeki yerleşim alanlarının içme suyu intiyacını karşılayan bölgenin önemli tatlı su kaynağıdır.

Beyşehir Gölü havza sınırları, gölün doğusunda kalan ovalık alan hariç dağlar ile çevrilidir. Gölün kuzeyinde yer alan ve tektonik süreçlerle bölgeye gelen Kızıldağ, kuzeydoğuda Sultandağları'nın uzantısı, batısı Anamas Dağları ve güneyi ise Gidengelmez Dağları ile sınırlandırılmıştır. Doğu tarafı nispeten tarımsal faaliyetlerin yoğunlaştığı peneplen bir topoğrafik özelliğe sahip alüvyonal ovalık alanlarla kaplıdır.

\section{Bölgesel Jeoloji}

Ketin (1966), tarafından Toridler olarak isimlendirilen çalışma alanının da içinde bulunduğu bölge bugünkü yapısını Alpin orojenezi ile kazanmıştır. Antalya Körfezi kuzeyinde, Toroslar'ın sivri ucu kuzeye doğru yönelmesi sonucunda yaklaşık ters "V" şeklini almıştır. Bu tektonik alan Blumenthal (1963) ve Koçyiğit (1981) tarafından "Isparta Büklümü", Brunn (1976), ve Şengör (1980) ise "Isparta Açısı" olarak tanımlanmıştır. Beyşehir Gölü'nün batı kıyısı boyunca Anamas Dağları eteğinde fay zonu uzanmaktadır. Sözü edilen oluk, faylı bir subsidans havzası niteliğindedir (Güngör, 2003).

Havzanın bugünkü yapısını kazanmasında tektonik hareketler kadar etkin olan karstlaşma, Neojende daha ileri düzeyde ortaya çıkmıştır. Toros Dağları'nın yükselmesini takiben bölgedeki karstlaşma süreci ilerlemiş ve yüzeydeki akarsu ağının yeraltı drenajı şekline geçmesi sağlanmıştır (Atalay, 1982).

Beyşehir Gölü havzasının tektonik özellikleri incelendiğinde, Beyşehir Gölü'nün oluşumunda iki büyük eğim atımlı fay ön plana çıkmaktadır. Bu faylardan birincisi Sultandağları ile göl arasında ikincisi ise Anamas Dağları ile göl arasındaki faydır. Beyşehir Gölü, Sultan Dağları ile Anamas Dağları arasında kalan kuzeybatı güneydoğu doğrultusundaki iki fay grubu arasında oluşmuş tektonik oluşumlu bir göldür. Göl batısındaki Anamas Dağları bir horst, Beyşehir Gölü ve Suğla Gölleri'nin de bulunduğu depresyon da bir graben karakterindedir (Biricik, 1982).

\section{Genel Jeoloji}

Beyşehir Gölü Havzası, doğusunda yer alan Sultan Dağları ile batısında bulunan Anamas Dağları'nı oluşturan litolojiler; Geyikdağı Birliğine ait formasyonlardır. Havzanın kuzeyinde Şarkikaraağaç Ovası, doğusunda Beyşehir ovası yer alır. Şarkikaraağaç Ovası'nın göl kıyısındaki kesimlerinde yaygın olarak Kızıldağ güneyinde ofiyolitik kayaçlar yüzeylenmektedir. Beyşehir Gölü'nün güneyinde yer alan Laleli ve Asmalıkaklık dağlarında Bozkır ve Geyikdağı Birliği'ne ait kayaçlar bulunmaktadır (Özgül, 1984). Benzer şekilde göl üzerinde adaların büyük bir bölümü Bozkır Birliği'ne ait kayaçlarla mostra vermektedir. Beyşehir Havzası'nda bulunan formasyonlar alttan üste doğru; Çaltepe Kireçtaşı (Alt-Orta Kambriyen), Sultandede Formasyonu (Üst Kambriyen-Ordovisiyen), Anamas Kireçtaşı (TriyasÜst Kretase), Hoyran Ofiyoliti (Üst Kretase), Büyükköprü Formasyonu (Eosen), Bağkonak Formasyonu (Neojen) ve Alüvyon (Kuvaterner) oluşturmaktadır. 


\section{Hidroloji}

Beyşehir Gölü beslenme havzası $4121 \mathrm{~km}^{2}{ }^{\prime} \mathrm{lik}$ bir alana sahip olmakla birlikte 8 tali havzaya ayrılmış olup, tali havzalar ve drenaj ağı haritası hazırlanmıştır (Şekil 2).

Çalışma alanındaki tali havzalardan en büyüğü olan Sarısu havzası 1134 km², kuzeyde Şarkikaraağaç havzası
$576,09 \mathrm{~km}^{2}$, doğuda Kıreli havzası 495,86 km², güneybatıda Yeşildağ havzası 446,26 km², batıda Yenişarbademli havzası 341,16 km², kuzeybatıda Gedikli havzası $236,42 \mathrm{~km}^{2}$, güneyde Üstünler havzası $166,97 \mathrm{~km}^{2}$ ve güneybatıda Karadiken havzası $58,39 \mathrm{~km}^{2}$ lik bir alanı kaplamaktadır. Çalışma alanı içerisinde yer alan Beyşehir Gölü'nün 1121 m kotundaki yüzey alanı ise 665,8 km²'dir (Tablo 1).

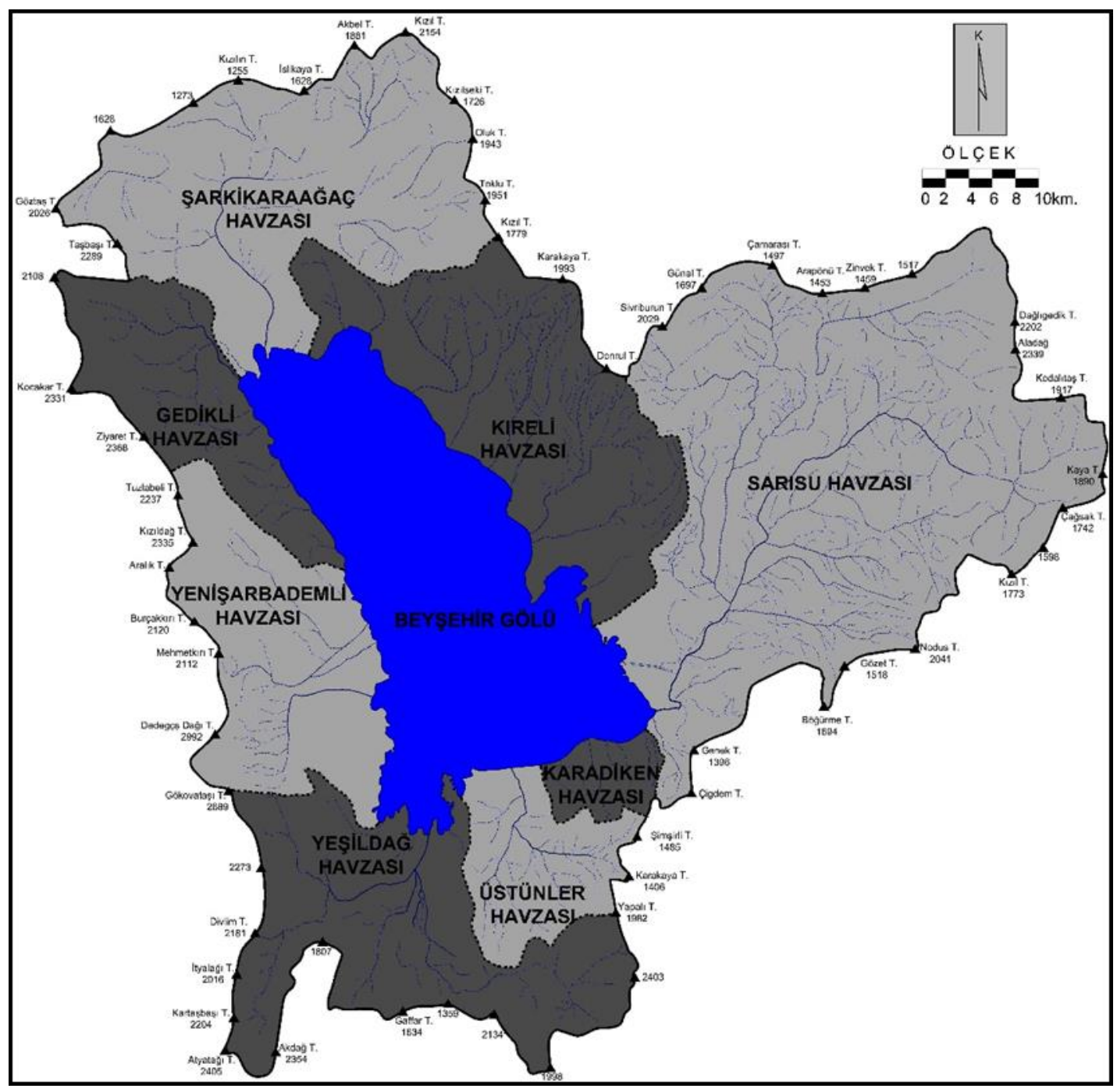

Şekil 2. Beyşehir Gölü beslenme havzası tali havzalar ve drenaj ağı haritası 
Tablo 1. Beyşehir Gölü tali havzaları ve özellikleri

\begin{tabular}{|l|c|c|}
\hline Havza Adı & İi & ALAN $\mathbf{( k m}^{\mathbf{2}} \mathbf{)}$ \\
\hline Şarkikaraağaç & Isparta & 576,09 \\
\hline Kıreli & Konya & 495,86 \\
\hline Sarısu & Konya & 1134,27 \\
\hline Karadiken & Konya & 58,39 \\
\hline Üstünler & Konya & 166,97 \\
\hline Yeşildağ & Konya & 446,26 \\
\hline Yenişarbademli & Isparta & 341,16 \\
\hline Gedikli & Isparta & 236,42 \\
\hline TOPLAM & & $\mathbf{3 4 5 5 , 4 2}$ \\
\hline Göl Alanı & & 665,8 \\
\hline Havza toplamı & & $\mathbf{4 1 2 1 , 2 2}$ \\
\hline
\end{tabular}

Gölün batı kıyısındaki düdenin kotu, göl su seviyesi kotunun üzerinde olduğu için bu düdenlerden kaçak olmadığı kabul edilebilir. Bu durumda, gölden kaçakların seviyeye bağlı olduğu söylenebilir. En büyük kaçak miktarı $29,7 \mathrm{~m}^{3} / \mathrm{sn}$ ile 1976 Mart ayında saptanmış olup ortalama kaçak miktarı ise 5 m³/sn'dir (Ekmekçi, 1987).

Beyşehir Gölü Havzasının beslenim elemanları; yüzeysel akış, yeraltısuyu beslenimi ve göl yüzeyine düşen yağışlardır. Boşalım elemanları ise; sulama, tahliye, buharlaşma ve karstik kaçaklardır. Gölü besleyen akarsular; Soğuksu, Üstünler, Yenişarbademli, Sarıöz, Eflatunpınarı, Ebülvefa, Kurucaova, Çavuş ve Ozan dereleridir. Gölün doğal deşarj noktası Beyşehir çayı göl çıkışından itibaren Seydişehir ovasını baştan başa kat edip ovanın diğer ucunda yer alan düşük kottaki Suğla Gölü yatağına mansap olmaktadır. Göl çıkışında yapılarak 1914 yılında tamamlanan regülatör aracılığıyla göl, tatlı su rezarvuarına dönüştürülmüştür.

Beyşehir Gölü'nün güneyinde yer alan Kızılova, Gembos ve Eynif ovalarından gelen kuzey-güney doğrultulu büyük bir fay boyunca Manavgat Çayı'na boşalmaktadır (Ayhan ve ark., 1996). Bu boşalıma ilave olarak gölün
Homat ve Küre burunlarında Mada Adası'nın doğusunda, Hacı Arif Adası ve Kül Adası civarındaki düdenler aracııı̆ıyla boşalım gerçekleşmektedir.

Beyşehir Gölü Havzası'nın doğusunda yer alan Hüyük İlçesi'ndeki köşk kaplıcası olarak adlandırılan termal kaynağın sıcaklığı $35-40{ }^{\circ} \mathrm{C}$ 'yi bulunmakta ve kaplıca olarak işletilmektedir (Yazıcıoğlu, 2007).

\section{Hidrojeoloji}

Bu bölümde çalışma alanında bulunan jeolojik birimler; hidrojeolojik özelliklerine göre sınıflandırılmış ve hidrojeoloji haritası hazırlanmıştır (Şekil 3). Jeolojik birimler; fiziksel özellikleri, sondaj loglarından elde edilen bilgiler ve hidrojeolojik özellikleri dikkate alınarak Taneli Gözenekli Akifer Ortam (Akf1), Erime Çatlaklı Kaya Akifer Ortam (Akf2), Akitard Ortam (Akt), Akiklüd Ortam (Akl), Akifüj Ortam 1 (Akj1) ve Akifüj Ortam 2 (Akj2) olmak üzere altı alt sınıf ayırt edilmiştir.

\section{Taneli Gözenekli Akifer Ortam (Akf1)}

Alüvyon ve yamaç molozundan meydana gelen taneli gözenekli akifer ortam (Akf1), en büyük yüzey alanını kuzeyde Şarkikaraağaç havzasında vermekte güneye doğru uzanarak Beyşehir Gölü kıyılarına kadar uzanmaktadır. Alüvyon, Beyşehir Gölü doğusunda kıyı şeridi boyunca güneye doğru uzanım göstermektedir. Birim, Beyşehir yerleşim alanı civarında ise değişen topoğrafya ile dere yataklarını takip eden dar bir koridor şeklinde havzanın kuzeydoğusuna doğru iç kesimlere kadar ve göl kenar çizgisini takiben güneye doğru dar bir şerit şeklinde alana yayılmaktadır.

Taneli gözenekli akifer ortam (Akf1) havzanın genelinden farklı olarak doğu kesimlerde yüksek rakımlardaki düzlük alanlarda geniş alanlar kaplamaktadır. Yeşildağ yerleşiminden güneye doğru iki farklı dere yatağını takiben içerilere doğru uzanmakta ve $38 \mathrm{~km}^{2}$ lik alanda yüzeylenmektedir. Benzer şekilde Beyşehir Gölü güneybatısındaki Yenişarbademli yerleşiminden dere yataklarını

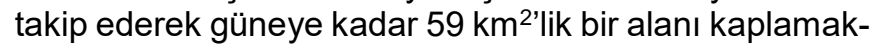
tadır. 


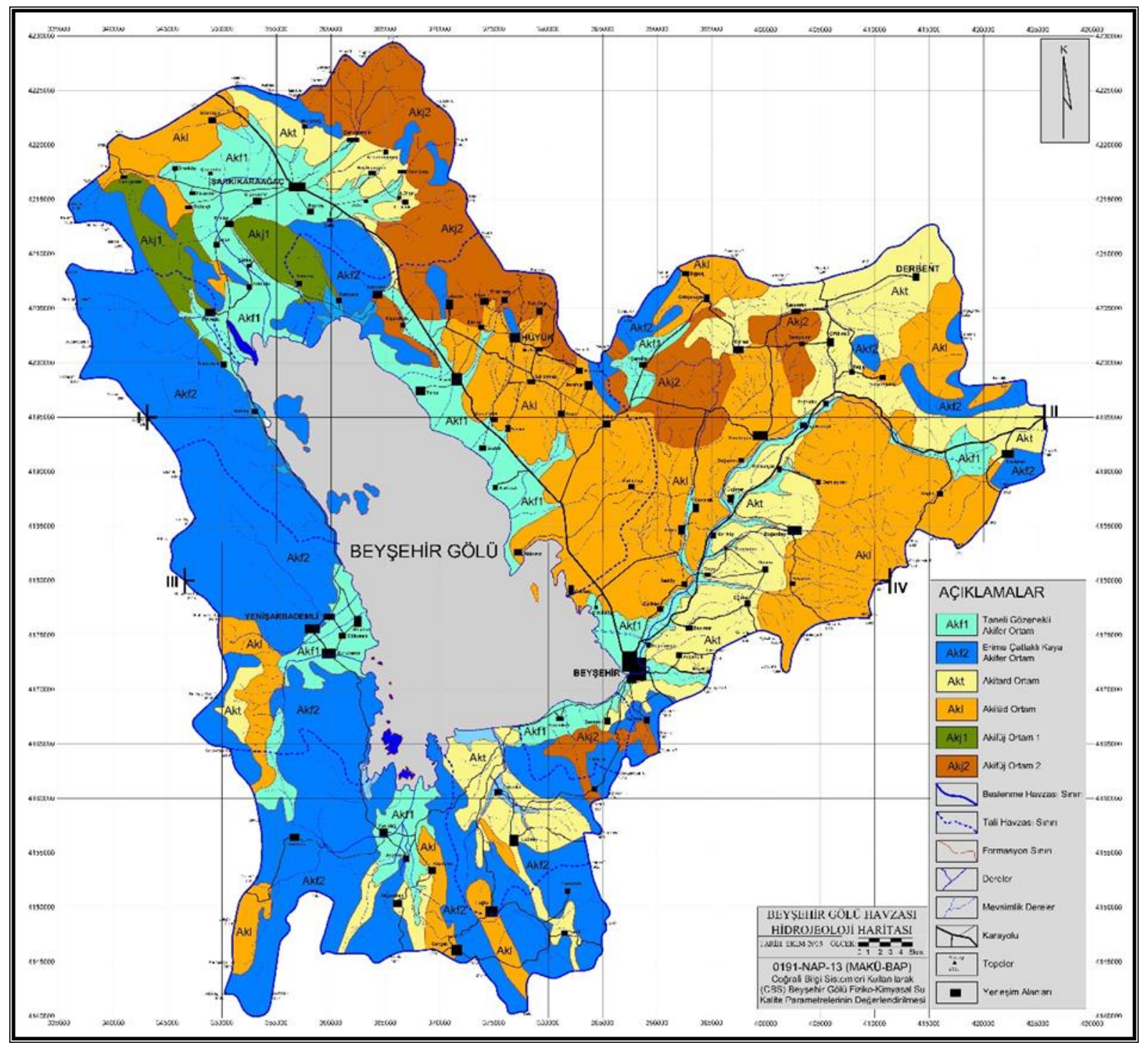

Şekil 3. Çalışma alanının hidrojeoloji haritası

\section{Erime Çatlaklı Kaya Ortam (Akf2)}

Çalışma alanında yüzeylenen kireçtaşları kırıklı-çatlaklı ve erime boşluklu yapılarından dolayı geçirimli erime çatlaklı kaya ortam (Akf2) olarak sınıflandırılmıştır. Birim içerisinde Anamas Dağları Grubuna ait Mesozoyik yaşlı kireçtaşları, bu grubun temelini oluşturan dolomit, dolomitik kireçtaşı ve yumrulu kireçtaşı içeren Çaltepe Formasyonu tanımlanmıştır (Eren, 1987; Dean and Monod, 1970; Öztürk ve ark., 1987). Bu birim içinde bulunan litolojilerin ortak özelliği, sahip oldukları kırık, çatlak ve erime boşluklarından dolayı karstik akifer özelliği taşımalarıdır. Bölgedeki karstik kireçtaşları da çatlak ve erime boşluklarında yeraltısuyu bulundurması bakımından büyük bir potansiyel oluşturmaktadır.

\section{Akitard Ortam (Akd)}

Çalışmanın stratigrafik ayrıtlamadan çok amacına uygun olarak birimlerin hidrojeolojik özellikleri baz alınmıştır. Bu birimi oluşturan Tersiyer yaşı bu tortullar genellikle karbonat çimentolu, çakıltaşı, kumtaşı ve konglomera gibi geçirgen litolojilerin ardalanmasından oluşmaktadırlar. Fakat zaman zaman çamurtaşı ve kiltaşı ardalanmaları olması sebebiyle geçirgenlikleri düşmekte ve tam bir akifer özelliği göstermemesi sebebiyle akitard ortam (Akd) olarak ayırt edilmiştir. Birim Şarkikaraağaç'ın doğusunda, Yenişarbademli'nin batısında ve Yeşildağ'ın güneyinde küçük alanlarda yüzeylenmektedir. Birimin çalışma alanında yüzeylendiği en geniş alan, Beyşehir'den kuzeydoğuya doğru Derbent'e kadar uzanan dar bir koridorda ve Derbent civarında görülmektedir. 


\section{Akiklüd Ortam (Akl)}

Tersiyer yaşlı tortullar genellikle kumtaşı, silttaşı ve kiltaşı seviyeleri ile başlayıp üstte kiltaşı, marn, killi kireçtaşı seviyelerine geçmektedir. Birimlerin içerisindeki tüfit ve kireçtaşı bol gözenekli olmasına rağmen marn, silis ve şist arakatkılı seviyeler birimlerin akifer olma özelliğini önemli ölçüde azalttığı için akiklüd ortam (Akl) olarak sınıflandırılmıştır. Marn ve kiltaşı bölümleri birimin su depolama ve iletme özelliğini kısıtlamaktadır. Birim Şarkikaraağaç havzasının kuzeyinde, Yenişarbademli havzasının batısında ve havzanın güneyinde küçük alanlarda yüzeylenmektedir. Birimin en geniş olarak gözlendiği alanlar ise çalışma alanının batısında yer almaktadır.

\section{Akifüj Ortam (Akj1)}

Beyşehir-Hoyran Hadim Napları içerisinde yer alan ofiyoliti, dunit, harzburjit, serpantinit, çört, peridodit ve farklı boyutlardaki olistrostromal kireçtaşı bloklarından oluşmaktadır. Ofiyolitik karmaşık içerisinde bulunan çört, peridodit ve serpantinitin ayrışması sonucu oluşan killerden dolayı birim akifer özelliği taşımaması sebebiyle akifüj ortam (Akj1) olarak adlandırılmıştır. Birim çalışma alanında Beyşehir Gölü kuzeyinde Şarkikaraağaç havzası içerisinde yer almaktadır. Beyşehir Gölü güneyinde yerel olarak serpantinitin yüzeylendiği alanlar bulunsa da haritalanacak büyüklükte görülmemiştir.

\section{Akifüj Ortam (Akj2)}

Sultandede Formasyonu olarak adlandırılan birim çalışma alanının altında yer almakta ve kuvarsit, rekristlize kireçtaşı, arakatkılı metakumtaşı, metaçakıltaşı, sleyt, fillit ve kalın katmanlı mermerden oluşmaktadır. Metamorfik masifi oluşturan kayaçlar esas olarak değişik metamorfizma dereceleri gösteren şistlerdir (Erişen, 1972; Demirkol ve ark., 1977). Sultandede Formasyonu düşük yeşilşist fasiyesi üzerine çıkamayan metamorfizmanın etkisinde kalmıştır. Birim içerisinde bulunan rekristalize kireçtaşı ve mermerler düşük miktarda yeraltısuyu bulundurmalarına rağmen, birimin metamorfik kökenli olması nedeniyle geçirimsiz olarak kabul edilmiş ve akifüj ortam (Akj2) olarak tanımlanmıştır. Sultandede Formasyonu özellikle Beyşehir Gölü kuzeyinden doğusuna kadar uzanım gösteren geniş bir alanda yüzeylenmektedir. Ayrıca çalışma alanı güneyinde dar bir alanda da haritalanmıştır.

\section{Yeraltısuyu Dinamiği}

Çalışma alanında resmi kurumlara ait toplam 42 derin sondaj kuyusuna ait teknik bilgiler ilgili kurumlardan alınarak değerlendirilmiştir (Tablo 2). Sondaj kuyularının teknik özellikleri dikkate alınarak, buradaki akifer karakteristikleri ve hidrojeolojik birimlerin hidrodinamik özelliklerine göre ayırt edilmişlerdir.

Çalışma alanındaki diğer sondaj kuyularının tamamının debi değerleri $15 \mathrm{l} / \mathrm{sn}$ 'nin altındadır. Debi değerleri 15 I/sn üzerindeki kuyuların kendi içerisindeki karakteristikleri incelendiğinde Sadıkhacı civarındaki sondaj kuyuları ve diğerleri olmak üzere iki farklı gruba ayrılmaktadır. Sadıkhacı ve civarındaki sondaj kuyularının en belirgin özellikleri derinliklerinin $39 \mathrm{~m}$ ile $59 \mathrm{~m}$ arasında değişmesine rağmen $15 \mathrm{l} / \mathrm{sn}$ ile $54 \mathrm{l} / \mathrm{sn}$ arasında değişen yüksek verimli debi değerlerine sahip olmalarıdır. Diğer grup sondaj kuyularını kendi içerisinde değerlendirdiğimizde Yenidoğan, Doğanbeyi Göcü ve Eğirler arasındaki sondaj kuyuları bir grup, Karaali civarındaki sondaj kuyuları ayrı bir grup olarak sınıflanabilir. Yenidoğan, Doğanbeyi Göcü ve Eğirler arasındaki sondaj kuyularının derinlikleri $110 \mathrm{~m}$ ile $155 \mathrm{~m}$ arasında iken debi değerleri $16 \mathrm{l} / \mathrm{sn}$ ile $45 \mathrm{l} / \mathrm{sn}$ arasındadır. Karaali civarındaki sondaj kuyularının derinlikleri ise $125 \mathrm{~m}$ ile $161 \mathrm{~m}$ arasında debileri ise $20 \mathrm{l} / \mathrm{sn}$ ile $28 \mathrm{l} / \mathrm{sn}$ arasında değişmektedir.

Bu değişimin temel nedeni, Sadıkhacı civarındaki sondaj kuyularının göle yakın olması ve kuyularda kesilen Akiklüd Ortamın (Akl) kalınlığının az olmasıdır. Diğer grup sondaj kuyularının göle uzak olması Akiklüd Ortamın (Akl) kalınlığının daha fazla olması ve sebebi ile sondaj kuyularının derinliklerinin deki artışı debi değerlerini artırmaktadır. Bölgedeki tüm sondaj kuyuları Gözenekli Akifer Ortam (Akf1) ve Akitard Ortam (Akd) ortamdan yeraltısuyu almaktadır.

Beyşehir Gölü havzasındaki mevcut tüm sondaj kuyularının lokasyonları gerek resmi kayıtlar ve gerekse arazi gözlemleri değerlendirildiğinde, genellikle çalışma alanının doğu kesiminde yoğunlaştığı görülmektedir. Beyşehir Gölü doğusundaki sondaj kuyularının büyük bölümü yerleşim alanlarına yakındır. Çalışma alanının doğu kesimindeki kuyular özellikle kuzeyden güneye doğru Değirmenaltı ve Mutlu civarı, Köşk ve Selki civarı, Doğanbey-Gündoğdu-Sevindik ve Karabayat civarı, Küçük Afşar-Bayat ve Beyşehir civarı olmak üzere 4 farklı bölgede toplanmaktadır. Bu bölgelerin jeolojik ve hidrodinamik özellikleri genellikle birbirine benzemekle birlikte daha peneplen bir topoğrafya hakimdir. Fakat çalışma alanının batı kesimindeki Erime Çatlaklı Kaya Ortamın (Akf2) bulunduğu alanda topoğrafya daha sarp ve eğim daha fazladır. 
Tablo 2. Çalışma alanındaki sondaj kuyularına ait teknik bilgiler

\begin{tabular}{|c|c|c|c|c|c|c|c|c|c|c|}
\hline \multirow{2}{*}{ No } & \multirow{2}{*}{$\begin{array}{l}\text { Kuyu } \\
\text { Adı }\end{array}$} & \multirow{2}{*}{$\begin{array}{r}\text { Derinlik } \\
(\mathrm{m}) \\
\end{array}$} & \multirow{2}{*}{$\begin{array}{r}\text { Rakım } \\
(\mathrm{m})\end{array}$} & \multirow{2}{*}{$\begin{array}{c}\text { Statik } \\
\text { Yass }\end{array}$} & \multirow{2}{*}{\begin{tabular}{|l|} 
Dinam \\
ik Yass
\end{tabular}} & \multirow{2}{*}{\begin{tabular}{|c} 
Yas Kotu \\
$(\mathrm{m})$
\end{tabular}} & \multirow{2}{*}{\multicolumn{2}{|c|}{$\begin{array}{c}\text { Akifer Derinliği } \\
(\mathrm{m})\end{array}$}} & \multicolumn{2}{|c|}{ Verim $(\mid t / s n)$} \\
\hline & & & & & & & & & $\mathrm{QA}$ & QP \\
\hline 1 & 1143 & 170,00 & 1027,00 & 2,80 & 18,55 & 1024,20 & & & & 13,60 \\
\hline 2 & 1151 & 103,40 & 1130,00 & 3,20 & 15,34 & 1126,80 & & & & 9,10 \\
\hline 3 & 1162 & 135,45 & 1133,00 & 3,50 & 20,90 & 1129,50 & & & & 4,50 \\
\hline 4 & 1165 & 193,50 & 1158,00 & 0,25 & 30,00 & 1157,75 & & & & 2,40 \\
\hline 5 & 1166 & 61,80 & 1197,00 & 9,50 & 30,00 & 1187,50 & & & & 7,20 \\
\hline 6 & 8157 & 141,00 & 1135,00 & 13,75 & 59,80 & 1121,25 & 73,00 & 100,00 & & 0,70 \\
\hline 7 & 8391 & 94,00 & 1210,00 & 0,00 & 24,65 & 1210,00 & 0,00 & 73,00 & & 6,00 \\
\hline 8 & $8416 \mathrm{~B}$ & 35,00 & 1205,00 & 2,40 & 14,00 & 1202,60 & 0,00 & 20,00 & & 8,00 \\
\hline 9 & 21552 & 187,70 & 1194,00 & 0,40 & 47,11 & 1193,60 & 29,00 & 165,00 & & 19,03 \\
\hline 10 & 33138 & 148,00 & 1212,00 & 23,50 & 54,00 & 1188,50 & 24,00 & 129,00 & & 10,00 \\
\hline 11 & 33986 & 153,00 & 1208,00 & 2,00 & 57,00 & 1206,00 & 4,00 & 126,00 & & 4,00 \\
\hline 12 & 34946 & 155,00 & 1200,00 & 26,00 & 48,00 & 1174,00 & 37,00 & 122,00 & & 40,00 \\
\hline 13 & 36518 & 110,00 & 1198,00 & 9,30 & 14,86 & 1188,70 & 20,00 & 101,00 & & 45,00 \\
\hline 14 & 36792 & 57,00 & 1175,00 & 11,00 & 34,00 & 1164,00 & 16,00 & 48,00 & & 15,00 \\
\hline 15 & 367938 & 57,00 & 1174,00 & 3,20 & 17,00 & 1170,80 & 16,00 & 32,00 & & 54,00 \\
\hline 16 & 36794 & 51,00 & 1169,00 & 13,00 & 25,60 & 1156,00 & 20,00 & 34,00 & & 15,30 \\
\hline 17 & $36795 \mathrm{~A}$ & 129,00 & 1165,00 & 10,40 & 33,50 & 1154,60 & 20,00 & 57,00 & & 4,00 \\
\hline 18 & 367958 & 51,00 & 1173,00 & 6,00 & 22,00 & 1167,00 & 12,00 & 32,00 & & 15,00 \\
\hline 19 & 36796 & 59,00 & 1178,00 & 11,50 & 31,00 & 1166,50 & 17,00 & 41,00 & & 30,00 \\
\hline 20 & 36797 & 39,00 & 1175,00 & 3,50 & 20,00 & 1171,50 & 20,00 & 36,00 & & 43,00 \\
\hline 21 & 39421 & 129,00 & 1195,00 & 30,00 & 60,00 & 1165,00 & 28,00 & 117,00 & & 2,00 \\
\hline 22 & 42490 & 146,00 & 1237,00 & 0,00 & 62,00 & 1237,00 & 16,00 & 138,00 & & 16,00 \\
\hline 23 & 42731 & 150,00 & 1215,00 & 32,00 & 53,00 & 1183,00 & 32,00 & 122,00 & & 42,00 \\
\hline 24 & 42732 & 150,00 & 1230,00 & 33,00 & 72,00 & 1197,00 & 32,00 & 130,00 & & 27,00 \\
\hline 25 & $42733 \mathrm{~A}$ & 150,00 & 1241,00 & 7,00 & 74,00 & 1234,00 & 31,00 & 134,00 & & 7,00 \\
\hline 26 & 427338 & 140,00 & 1239,00 & 15,00 & 75,00 & 1224,00 & 15,00 & 95,00 & & 3,00 \\
\hline 27 & 42734 & 150,00 & 1248,00 & 5,00 & 69,00 & 1243,00 & 24,00 & 134,00 & & 28,00 \\
\hline 28 & 43760 & 161,00 & 1290,00 & 8,00 & 60,00 & 1282,00 & 32,00 & 138,00 & & 20,00 \\
\hline 29 & 46786 & 140,00 & 1220,00 & 28,00 & 56,00 & 1192,00 & 32,00 & 125,00 & & 43,00 \\
\hline 30 & 46787 & 133,00 & 1193,00 & 18,00 & 41,00 & 1175,00 & 28,00 & 125,00 & & 43,00 \\
\hline 31 & 47675 & 145,00 & 1189,00 & 6,00 & 70,00 & 1183,00 & 28,00 & 133,00 & & 3,00 \\
\hline 32 & 47769 & 120,00 & 1209,00 & 5,00 & 27,00 & 1204,00 & 12,00 & 106,00 & & 6,00 \\
\hline 33 & 51289 & 125,00 & 1291,00 & 9,00 & 54,00 & 1282,00 & 24,00 & 117,00 & & 28,00 \\
\hline 34 & 51291 & 128,00 & 1310,00 & 0,00 & 78,00 & 1310,00 & 24,00 & 120,00 & & 10,00 \\
\hline 35 & 4759 & 142,00 & 1133,00 & 3,00 & 40,90 & 1130,00 & 55,00 & 142,00 & & 10,00 \\
\hline 36 & 199 & 100,00 & 1181,00 & 11,00 & 33.38 & 1170,00 & 6,00 & 62,00 & 1,00 & \\
\hline 37 & 4326 & 62,00 & 1166,00 & 4,70 & 20,70 & 1161,30 & 2,00 & 62,00 & 30,00 & \\
\hline 38 & $3571 \mathrm{~A}$ & 52,00 & 1163,00 & 3,25 & 4,00 & 1159,75 & 20,00 & 43,00 & 8,00 & \\
\hline 39 & $3571 B$ & 52,00 & 1163,00 & 3,25 & 28,00 & 1159,75 & 19,00 & 43,00 & 8,00 & \\
\hline 40 & 4431 & 40,00 & 1135,00 & 4,00 & 19,30 & 1131,00 & 0,00 & 35,00 & 3,00 & \\
\hline 41 & 2353 & 36,00 & 1226,00 & 8,45 & 17,40 & 1217,55 & 0,00 & 12,00 & 2,00 & \\
\hline 42 & 2818 & 80,00 & 1262,00 & 10,35 & 16,70 & 1251,65 & 13,00 & 80,00 & 8,00 & 3,00 \\
\hline 43 & 2817 & 23,00 & 1265,00 & 4,30 & 7,05 & 1260,70 & 10,00 & 23,00 & 6,00 & \\
\hline
\end{tabular}


Çalışma alanı için yeraltısuyu seviye haritası 2014 ve 2015 yıllarında arazi çalışmaları sırasında ölçülen yeraltısuyu seviyelerinin ortalaması baz alınarak alüvyon litoloji ile temsil edilen taneli ortam akiferi olarak tanımlanan
Gözenekli Akifer Ortam (Akf1) için hazırlanmıştır (Şekil 4).

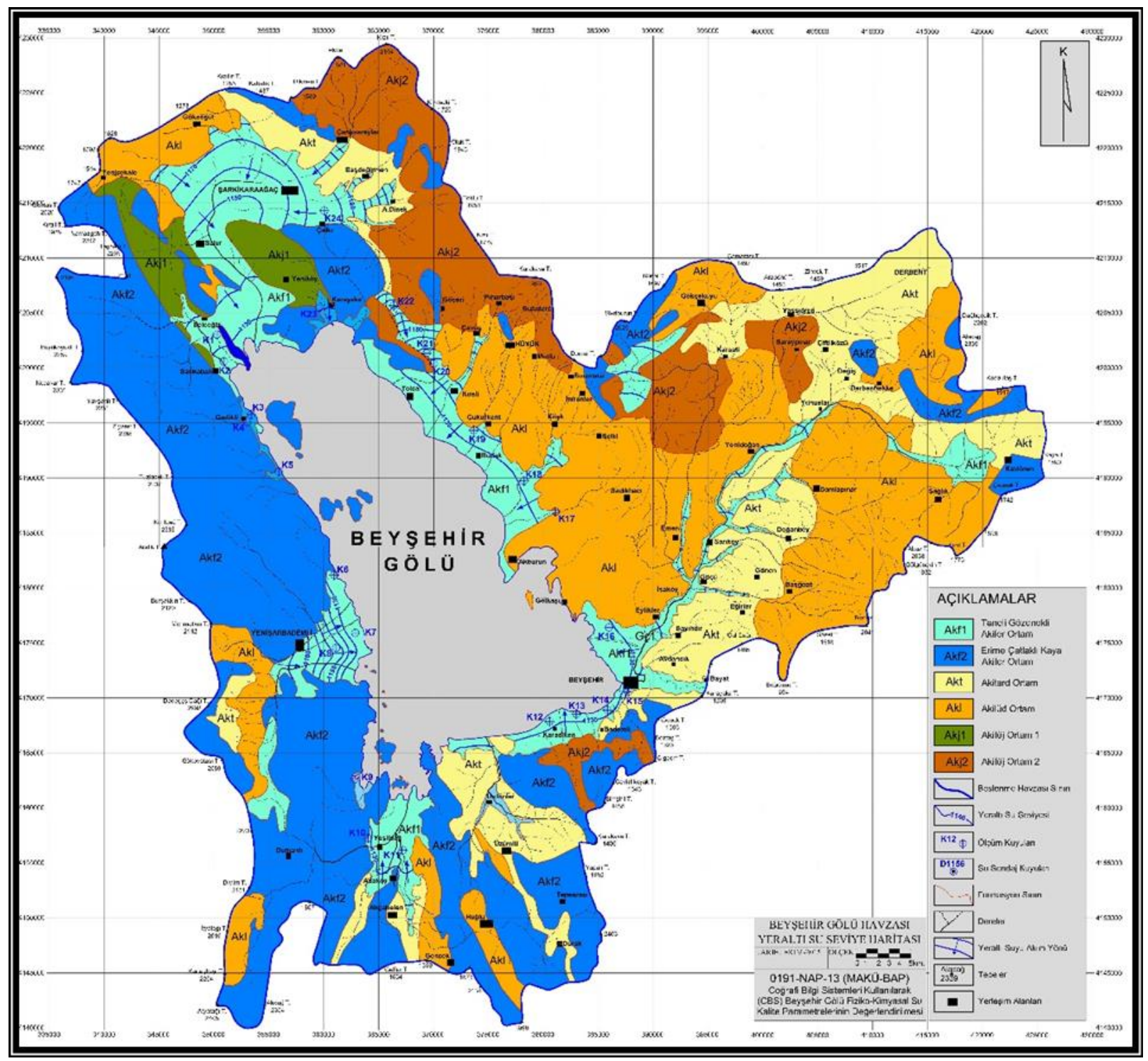

Şekil 4. Çalışma alanının yeraltısuyu seviye haritası

Yeraltısuyu seviye haritası incelendiğinde çalışma alanının doğu kesiminde gözenekli akiferlerin, batı kesimde karstik karakterdeki erime çatlaklı kaya ortam akiferin bulunduğu dikkati çekmektedir. Çalışma alanının batısındaki gözenekli akiferin hakim olduğu alanlarda yeraltısuyu akım eğrileri çok daha sık ve hidrolik eğim fazla iken batı kesiminden bunun tam tersine yeraltısuyu akım eğrileri daha seyrek hidrolik eğim daha düşüktür. Çalışma alanının genelinde yeraltısuyu akım yönü Beyşehir Gölü'ne doğrudur, istisna olarak gölün kuzey doğusunda Göçeri batısındaki Akifüj Ortamı (Akj2) ile sınırlandırılmış vadi boyunca yeraltısuyu akım yönü önce güneye sonra göle doğrudur.

Gölün kuzeyinde yer alan Şarkikaraağaç ovasında ise güney batı ve güney doğu yönlerindeki yeraltısuyu akım yönü Kızıldağ milli parkı civarındaki Taneli Gözenekli Akifer Ortamın (Akf1) batısından güney doğu yönünde göle doğrudur.

Gölün batısındaki sarp topoğrafik yüzey boyunca mostra veren Erime Çatlaklı Kaya Ortamı (Akf2) karstik özellikte olup erime boşluklu kaya ortam akifer özelliğindedir. Bu 
birimin üzerinde daha düz alanlarda alüvyon ve sarp kesimlerde yamaç molozu birimi yüzeylenmektedir. Bu kesimlerdeki yeraltısuyu akım yönü doğrudan doğu yönünde göle doğru gerçekleşmektedir.

Çalışma alanının güneyinde bulunan Yeşildağ ve Adaköy civarında ise hakim yüzeysel akışa benzer şekilde topoğrafik eğime uygun olarak yeraltısuyu akım yönü kuzeye doğrudur. Karadiken ve Bademli arasındaki sahil şeridi boyunca gelişen alüvyon alandaki yeraltısuyu eğimi, kıyı şeridine yaklaşık paralel olarak Beyşehir ilçesine kadar uzanmakla birlikte genel olarak Beyşehir Gölü'ne doğrudur.

\section{Model Alanının ve Grid Ağlarının Oluşturulması}

Akifer sistem sınır koşulları modeli Groundwater Vistas 5 (GW5) programında, çalışma alanı ortasında Beyşehir Gölü sabit seviyeli hidrolik yük ve diğer sınırların tamamı ise akım olmayan (sıfır akım) sınır koşulları olarak modellenebilir. Yeraltısuyu akım denklemi yalnızca aktif olarak modellenen akifer sistemi için kullanılmaktadır.
Sabit seviye hidrolik yük olarak modellenebilecek olan Beyşehir Gölü ise, akifer sistemindeki aktif bölgenin su seviyelerine bağlı olarak akiferden beslenen veya akiferi besleyen bir alan olarak tanımlanır. Beslenme havzası sınırları dışındaki hücreler aktif olmayan hücreler olarak isimlendirilmekte ve yeraltısuyu akım denklemine katımamaktadır.

Çalışma alanı 36. UTM bölgesine karşılık gelen $335000 \mathrm{E}, 4140000 \mathrm{~N}$ ve $426000 \mathrm{E}, 4230000 \mathrm{~N}$ koordinatları arasında kalan x yönünde $90 \mathrm{~km}$, y yönünde $91 \mathrm{~km}$ olmak üzere $8190 \mathrm{~km}^{2}$ lik bir alanı kaplamaktadır. Modelin güney batı köşesi orijin olarak alınarak $x=y=0$ noktası yerine $x=335000 E$ ve $y=4140000 N$ UTM başlangıç koordinatları kabul edilerek, tüm veriler UTM koordinatları kullanılarak girilmiştir. Model alanı $4064 \mathrm{~km}^{2} \mathrm{lik}$ alanı temsil eden inaktif hücreler çıktıktan sonra akifer sisteminin aktif model alanı $3476 \mathrm{~km}^{2}$, Beysehir Gölü sabit seviye alanı ise $650 \mathrm{~km}^{2}$ 'dir. Çalışma alanı sonlu farklar modeline göre değişken büyüklükte 90 x 91 olmak üzere 8190 hücreden oluşan grid ağına bölünmüştür (Şekil 5).

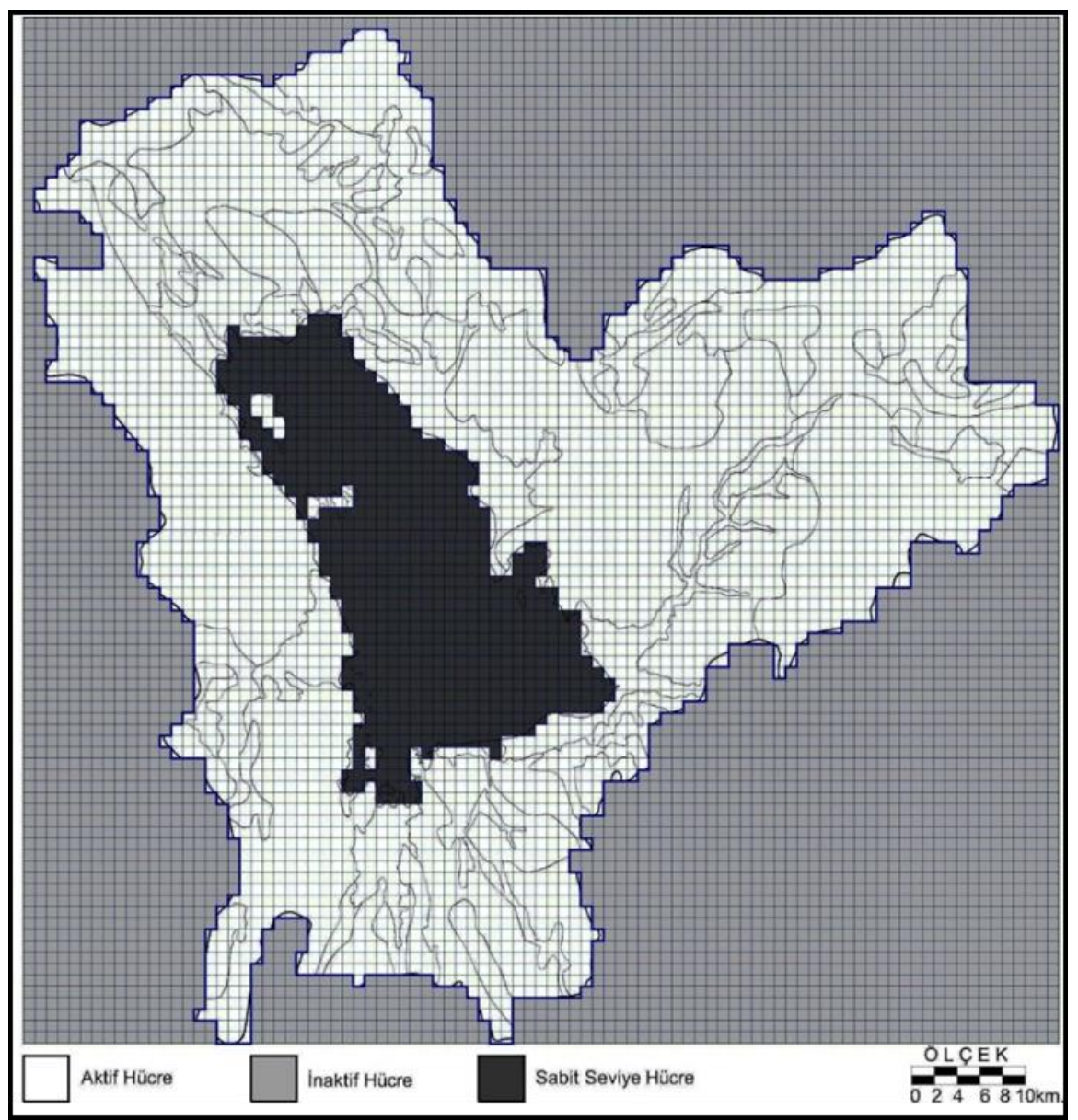

Şekil 5. Çalışma alanının hidrojeoloji haritası baz alınarak oluşturulan sonlu farklar grid ağı 
MODFLOW akım modelinde IBOUND düzeni olarak isimlendirilen sınır şartlarının girilmesi gerekmektedir. IBOUND düzeninde her bir model ve modeldeki her bir hücrenin modelde sabit yük, aktif veya aktif olmayan hücre olduğunu belirten kodları içinde bulunduran bir matris vardır. IBOUND düzeninde aktif hücreler pozitif bir değer, sabit seviye hücreler negatif bir değer, akışın olmadığı inaktif hücreler ise sıfır (0) değeri ile tanımlanmaktadır. Sabit seviye hücrelerin aynı benzetim içerisinde başlangıç hidrolik seviyeleri değişmemektedir. Bir akifer ne zaman göl, nehir veya bir rezervuar ile doğrudan bir hidrolik ilişki içinde olursa o zaman sabit seviye sınırlar söz konusu olmaktadır. Model alanı ortasında yer alan Beyşehir Gölü sabit seviye sınırlara örnek olarak verilebilir.

Çalışma alanında jeolojik ve hidrojeolojik özelliklerin çok karmaşık ve değişken olmasından dolayı farklı boyutlarda grid hücreleri kullanılarak detaylandırımalıdır. Jeolojik ve hidrojeolojik parametrelerin dar alanlarda değişim gösterdiği bölgelerde küçük hücreler, homojen dağılım gösterdiği bölgelerde büyük hücreler yerleştirilmelidir.

\section{SONUÇ VE TARTIŞMA}

Çalışma alanı Türkiye'nin önemli karst bölgelerinden biri olan Toros Karst Kuşağının Batı Toroslar kesiminde Isparta Büklümü içerisinde yer almaktadır. Türkiye'nin 25 akarsu havzasına ayrıldığı, Türkiye akarsu havzaları haritasına göre Beyşehir Gölü Havzası, Konya Kapalı Havzası içerisinde yer almaktadır.

Konya ve Isparta il sınırı içerisinde yer alan Beyşehir Gölü Su Toplama Havzası, bünyesinde 8 tali havzayı barındıran ve yaklaşık $4121 \mathrm{~km}^{2}$ büyüklüğü ile Türkiye'nin en büyük tatlı su gölüdür. Beyşehir Gölü çevresindeki yerleşim alanlarının içme suyu ve tarım alanlarının sulama suyu intiyacını karşılayan bölgenin önemli tatı su kaynağıdır.

Beyşehir Gölü'nün oluşumunda iki büyük eğim atımlı fay ön plana çıkmaktadır. Göl, Sultan Dağları ile Anamas Dağları arasında kalan kuzeybatı güneydoğu doğrultusundaki iki fay grubu arasında oluşmuş tektonik oluşumlu bir göldür.

Beyşehir Havzası'nda bulunan jeolojik birimler litolojik özelliklerine göre alttan üste doğru; Çaltepe Kireçtaşı (Alt-Orta Kambriyen), Sultandede Formasyonu (Üst Kambriyen-Ordovisiyen), Anamas Kireçtaşı (Triyas-Üst Kretase), Hoyran Ofiyoliti (Üst Kretase), Büyükköprü Formasyonu (Eosen), Bağkonak Formasyonu (Neojen) ve Alüvyon'dan (Kuvaterner) oluşmaktadır.
Beyşehir Gölü Havzasının beslenim elemanları; yüzeysel akış, yeraltısuyu beslenimi ve göl yüzeyine düşen yağışlardır. Boşalım elemanları ise; sulama, tahliye, buharlaşma ve karstik kaçaklardır. Jeolojik birimler; fiziksel özellikleri, sondaj loglarından elde edilen bilgiler ve hidrojeolojik özellikleri dikkate alınarak Taneli Gözenekli Akifer Ortam (Akf1), Erime Çatlaklı Kaya Akifer Ortam (Akf2), Akitard Ortam (Akt), Akiklüd Ortam (Akl), Akifüj Ortam 1 (Akj1) ve Akifüj Ortam 2 (Akj2) olmak üzere altı alt sınıf ayırt edilmiştir.

Çalışma alanının batısındaki gözenekli akiferin hakim olduğu alanlarda yeraltısuyu akım eğrileri çok daha sık ve hidrolik eğim fazla iken batı kesiminde bunun tam tersine yeraltısuyu akım eğrileri daha seyrek hidrolik eğim daha düşüktür. Çalışma alanının genelinde yeraltısuyu akım yönü Beyşehir Gölü'ne doğrudur, istisna olarak gölün kuzey doğusunda Göçeri batısındaki Akj2 ortamı ile sınırlandırılmış vadi boyunca yeraltısuyu akım yönü önce güneye sonra göle doğrudur. Gölün kuzeyinde yer alan Şarkikaraağaç ovasında ise güney batı ve güney doğu yönlerindeki yeraltısuyu akım yönü Kızıldağ milli parkı civarındaki Akf1 ortam batısından güney doğu yönünde göle doğrudur. Gölün batısındaki sarp topoğrafik yüzey boyunca mostra veren Akf2 ortamı karstik özellikte olup erime boşluklu kaya ortam akifer özelliğindedir. Çalışma alanının güneyinde bulunan Yeşildağ ve Adaköy civarında ise hakim yüzeysel akışa benzer şekilde topoğrafik eğime uygun olarak yeraltısuyu akım yönü kuzeye doğrudur. Karadiken ve Bademli arasındaki sahil şeridi boyunca gelişen alüvyon alandaki yeraltısuyu eğimi, kıyı şeridine yaklaşık paralel olarak Beyşehir ilçesine kadar uzanmaktadır. Çalışma alanında yeraltısuyu akım yönü genel olarak topoğrafik eğime uygun olarak göle doğru gerçekleşmektedir.

Çalışma alanı için yeraltısuyu akım modellemesinde kullanılabilecek, model alanı 4064 km²'lik alanı temsil eden inaktif hücreler çıktıktan sonra akifer sisteminin aktif model alanı $3476 \mathrm{~km}^{2}$, Beysehir Gölü sabit seviye alanı ise $650 \mathrm{~km}^{2}$ dir. Çalışma alanı sonlu farklar modeline göre değişken büyüklükte 90 x 91 olmak üzere 8190 hücreden oluşan grid ağına bölünmüştür.

Çalışma alanında jeolojik ve hidrojeolojik özelliklerin çok karmaşık ve değişken olmasından dolayı farklı boyutlarda grid hücreleri kullanılarak detaylandırılmalıdır. Jeolojik ve hidrojeolojik parametrelerin dar alanlarda değişim gösterdiği bölgelerde küçük hücreler, homojen dağılım gösterdiği bölgelerde büyük hücreler yerleştirilmelidir.

\section{TEŞEKKÜR}

Bu çalışma, Mehmet Akif Ersoy Üniversitesi, Bilimsel Araştırma Projeleri Yönetim Birimi tarafından 0119- 
NAP-13 nolu Normal Araştırma Projesi ile desteklenmiştir.

\section{KAYNAKLAR}

Atalay, İ. (1982). Türkiye Jeomorfolojisine Giriş, Genişletilmiş 2. Baskı, Ege Üniversitesi, Edebiyat Fakültesi, Yayın No:9, $456 \mathrm{~s}$.

Ayhan, A., Güzel, A., Küçüködük, M., Durak, Y., Obalı, O., Tütüncü, T. (1996). Beyşehir Gölü'nün Su Kaynaklarının Korunması, Kimyasal ve Bakteriyolojik Kirliliğin Araştırılması. TÜBITAK DEBAG-31/DPT Nolu Proje Sonuç Raporu, s.138.

Biricik, A. S. (1982). Beyşehir Gölü Havzasının Strüktürel ve Jeomorfolojik Etüdü, İstanbul Üniversitesi Yayın No:2867, Coğrafya Enstitüsü Yayınları, No:119, 250 s.

Blumenthal, M. (1963). Le Systéme Structural du Taurus SudAnotolien: in Livre à La mémoire du Professeur P. Fallot, Mém. hs. sér. Soc. Géol. France, 2, 611-622 s.

Brunn, J.H. (1976). L'arc Concave Zagro-Taurique Et Les Arcs Convexes Taurique Et Egeen, Collision Et İnduits, Bull. Soc. Geol. France, (7) XVIII, No:2 553-567.

Doğan, A. Başyiğit, L., Soyaslan, İ., Nas, B. (2013). Göl-Yeraltısuyu-İklim İlişkisinin Yeraltısuyu Akım Modeli ve Coğrafi Bilgi Sistemleri (CBS) Yardımıyla Belirlenerek Gölün Optimum Dinamik İşletme Modelinin Oluşturulması: Beyşehir Gölü Modeli. TÜBITAK 109Y271 Nolu Proje Sonuç Raporu, s. 137.

Dean, W.T., Monod, O. (1970). The Lower Palaeozoic stratigraphy and faunas of the Taurus Mountains near Beyflehir, Turkey. I. Stratigraphy. Bulletin of the British Museum (Natural History), Geology 19, 413-426.

Demirkol, C., Sipahi, H., Çiçek, S., Barka, A., Sönmez, Ş. (1977). Sultandağının Stratigrafisi ve Jeoloji Evrimi, MTA Enstitüsü Jeoloji Dairesi, MTA raporu, Yayımlanmamış, Derleme No:6305.

DSI (1996). Beyşehir Gölü Hidrolojisi Raporu. Devlet Su İşleri Genel Müdürlüğü, IV. Bölge Müdürlüğü, Konya.

DSi (2017). http://www.dsi.gov.tr/docs/resmi-i-statistikler/1-1t\%C3\%BCrkiye-havza-numaralar\%C4\%B1-ve-havzalar\%C4\%B1-2014.docx?sfvrsn=4 (Erişim Tarihi: $16 / 08 / 2017)$

Ekmekçi, M. (1987). Beyşehir Gölü'nün Komşu Havza Akımlarına Olan Etkilerinin Araştırılması, Y. Lisans Tezi, Hacettepe Üniversitesi, Fen Bilimleri Enstitüsü.
Eren, Y. (1987), Sultandağları Masif'nin strtigrafisi ve mesoskopik tektoniği, Yüksek lisans tezi (Yayımlanmamış). Selçuk Üniversitesi. Konya, $80 \mathrm{~s}$.

Erişen, B. (1972). Afyon-Heybeli (Kızılkilise) Jeotermal Araştırma Sahasının Jeolojisi ve Jeotermal Enerji Olanakları. MTA Raporu, Derleme No:3107 (Yayımlanmamış), Ankara.

Hoşafcıoğlu S. (2007), Beyşehir Gölü Havzası'nda Noktasal ve Noktasal Olmayan Kirletici Kaynakların Değerlendirilmesi, Selçuk Üniversitesi, Fen Bilimleri Enstitüsü, Yüksek Lisans Tezi, (Yayımlanmamış) s.134.

Güngör, S. (2003). Beyşehir İlçesi ve Yakın Çevresi Turizm ve Rekreasyon Kullanımına Yönelik Peyzaj Potansiyelinin Saptanması Üzerine Bir Araştırma, Ankara Üniversitesi, Fen Bilimleri Enstitüsü, (Yayımlanmamış) Doktora Tezi, Ankara.

Kazancı, N., Oğuzkurt, D., Dügel, M. (2003). Beyşehir Gölü'nün Limnolojisi, Çevre Kalitesi, Biyolojik Çeşitliliği ve Korunması, Türkiye İç Suları Araşatırma Dizisi: VII, İmaj Yayınevi, 148 s., Ankara.

Ketin, İ. (1966). Tectonic units of Anatolia (Asia Minor), Maden Tetkik Arama Dergisi, 66, 23-34.

Koçyiğit, A. (1981). Isparta Büklümünde (Batı Toroslar) Toros Karbonat Platformunun Evrimi, Türkiye Jeoloji Kurumu Bülteni, 24, 15-23.

Mercan, D.E. (2006). Beyşehir Gölü'nün Hidrodinamik Modellemesi, İstanbul Teknik Üniversitesi, Fen Bilimleri Enstitüsü, Doktora Tezi, s. 137 (Yayımlanmamış).

Özgül, N. (1984). Stratigraphy and Tectonic Evolution of the Central Taurides. Geology of the Taurus Belt. (eds., Tekeli, O. and Göncüoğlu, M.C.). International Symposium. 77-90 s., Ankara/Turkey.

Öztürk, E.M., Dalkılıç, H., Ergin, A., Avşar, Ö.P. (1987).Sultandağı güneydoğusu ile Anamasdağı dolayının jeolojisi Maden Tetkik Arama Enst.Rap. No:7045 (yayımlanmamış), Ankara.

Şengör, A.M.C. (1980). Türkiye'nin Neotektoniğinin Esasları Türkiye Jeoloji Kurultayı Konferanslar dizisi, 2, $40 \mathrm{~s}$.

Yarar, A. (2004). Beyşehir Gölü Seviyesi Değişimlerinin Yapay Sinir Ağları ile Belirlenmesi. Selçuk Üniversitesi, İnşaat Mühendisliği Anabilim Dalı, Yüksek Lisans Tezi, s. 99 (Yayımlanmamış).

Yazıcıoğlu, D. (2007). Hüyük-İmrenler-Burunsuz-Köşk (Beyşehir-Konya) Çevresinin Hidrojeoloji İncelemesi. Selçuk Üniversitesi, Fen Bilimleri Enstitüsü, Jeololoji Müh. Anabilim Dalı Yüksek Lisans Tezi, s.100 (Yayımlanmamış). 